\title{
Optimal PID power system stabilizer tuning based on particle swarm optimization
}

\author{
Sayed Mojtaba Shirvani Boroujeni, Reza Hemmati, Hamideh Delafkar and Amin Safarnezhad Boroujeni
}

Islamic Azad University, Boroujen Branch, Department of Electrical Engineering, Boroujen, Iran

Mo_shirvani@yahoo.com, reza.hematti@gmail.com, delafkar@aut.ac.ir, safarnezhad@gmail.com

\begin{abstract}
Power system stabilizers (PSS) are used to generate supplementary damping control signals for the excitation system in order to damp the low frequency oscillations (LFO) of the electric power system. The PSS is usually designed based on classical control approaches but this conventional PSS (CPSS) has some problems. To overcome the drawbacks of CPSS, numerous techniques have been proposed in literatures. In this paper a PID type PSS is considered for damping electric power system oscillations. The parameters of this PID type PSS are tuned based on particle swarm optimization method. The proposed PSS (PSO-PSS) is evaluated against the conventional power system stabilizer (CPSS) at a single machine infinite bus power system considering system parametric uncertainties. The simulation results clearly indicate the effectiveness and validity of the proposed method.
\end{abstract}

Keywords: Electric power system stabilizer, low frequency oscillations, particle swarm optimization.

Nomenclature: $\omega$ : Synchronous speed; $\delta$ : Synchronous angle; $P_{m}$ : Input mechanical power; $P_{\mathrm{e}}$ : Output electrical power; $M$ : Inertia; $E_{q}$ : $q$ axis voltage; $E_{\mathrm{fd}}$ : Field voltage; $\mathrm{E}_{\mathrm{q}}$ : Transient voltage of $\mathrm{q}$ axis; $\mathrm{T}_{\mathrm{do}}$ : Transient time constant of $\mathrm{q}$ axis; $\mathrm{K}_{\mathrm{a}}$ : Excitation system gain; $\mathrm{T}_{\mathrm{a}}$ : Excitation system time constant; $V_{t}$ : Terminals voltage; $V_{\text {ref: }}$ Reference voltage of excitation system; $\mathrm{T}_{\mathrm{m}}$ : Mechanical torque; PSS: Power system stabilizer; PSO: Particle swarm optimization; CPSS: Conventional power system stabilizer; PID: Proportional-integral-differential; PSO-PSS: Particle swarm optimizationPower system stabilizer; ITAE: Integral of the time multiplied absolute value of the error.

Introduction

Large electric power systems are complex non-linear systems and often exhibit low frequency electromechanical oscillations due to insufficient damping caused by adverse operating. These oscillations with small magnitude and low frequency often persist for long periods of time and in some cases they even present limitations on power transfer capability (Liu et al., 2005). In analyzing and controlling the power system's stability, two distinct types of system oscillations are recognized. One is associated with generators at a generating station swinging with respect to the rest of the power system. Such oscillations are referred to as "intra-area mode" oscillations. The second type is associated with swinging of many machines in an area of the system against machines in other areas. This is referred to as "inter-area mode" oscillations. Power system stabilizers (PSS) are used to generate supplementary control signals for the excitation system in order to damp both types of oscillations (Liu et al., 2005). The widely used conventional power system stabilizers (CPSS) are designed using the theory of phase compensation in the frequency domain and are introduced as a lead-lag compensator. The parameters of CPSS are determined based on the linearized model of the power system. Providing good damping over a wide operating range, the CPSS parameters should be fine tuned in response to both types of oscillations. Since power systems are highly non-linear systems, with configurations and parameters which alter through time, the CPSS design based on the linearized model of the power system cannot guarantee its performance in a practical operating environment. Therefore, an adaptive PSS which considers the non- linear nature of the plant and adapts to the changes in the environment is required for the power system (Liu et al., 2005). In order to improve the performance of CPSSs, numerous techniques have been proposed for designing them, such as intelligent optimization methods (Sumathi et al., 2007; Jiang et al., 2008; Sudha et al., 2009; Linda \& Nair, 2010; Yassami et al., 2010) and fuzzy logic method (Dubey, 2007; Hwanga et al., 2008). Also many other different techniques have been reported by Chatterjee et al. (2009) and Nambu and Ohsawa (1996) and the application of robust control methods for designing PSS has been presented by Gupta et al. (2005), Mocwane and Folly (2007), Sil et al. (2009) and Bouhamida et al. (2005). This paper deals with a design method for the stability enhancement of a single machine infinite bus power system using PID type PSS which its parameters are tuned using particle swarm optimization method (PSO-PSS). To show effectiveness of the new PID type PSO-PSS, this method is compared with the CPSS. Simulation results show that the proposed method guarantees robust performance under a wide range of operating conditions.

\section{System under study}

Fig. 1 shows a single machine infinite bus power system (Kundur, 1993). The static excitation system has

Fig. 1. A single machine infinite bus power system.

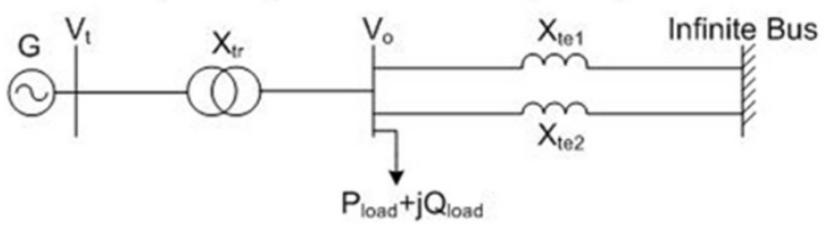

Research article

(CIndian Society for Education and Environment (iSee)
"Power system stabilizer" http://www.indjst.org
S.M.S.Bourojeni et al. Indian J.Sci.Technol. 
been considered as model type IEEE - ST1A.

\section{Dynamic model of the system}

Non-linear dynamic model

A non-linear dynamic model of the system is derived by disregarding the resistances and the transients of generator, transformers and transmission lines (Kundur, 1993). The non-linear dynamic model of the system is given as (1).

\section{Linear dynamic model}

A linear dynamic model of the system is obtained by linearizing the non-linear dynamic model around the nominal operating condition. The linearized model of the system is obtained as (2) (Kundur, 1993).

$$
\begin{aligned}
& \dot{\omega}=\frac{\left(\mathrm{P}_{\mathrm{m}}-\mathrm{P}_{\mathrm{e}}-\mathrm{D} \Delta \omega\right)}{\mathrm{M}} \\
& \dot{\delta}=\omega_{0}(\omega-1) \\
& \dot{\mathrm{E}}_{\mathrm{q}}^{\prime}=\frac{\left(-\mathrm{E}_{\mathrm{q}}+\mathrm{E}_{\mathrm{fd}}\right)}{\mathrm{T}_{\mathrm{do}}^{\prime}} \\
& \dot{\mathrm{E}}_{\mathrm{fd}}=\frac{-\mathrm{E}_{\mathrm{fd}}+\mathrm{K}_{\mathrm{a}}\left(\mathrm{V}_{\mathrm{ref}}-\mathrm{V}_{\mathrm{t}}\right)}{\mathrm{T}_{\mathrm{a}}} \\
& \Delta \dot{\delta}=\omega_{0} \Delta \omega \\
& \Delta \dot{\omega}=\frac{-\Delta \mathrm{P}_{\mathrm{e}}-\mathrm{D} \Delta \omega}{\mathrm{M}} \\
& \Delta \dot{\mathrm{E}}_{\mathrm{q}}^{\prime}=\left(-\Delta \mathrm{E}_{\mathrm{q}}+\Delta \mathrm{E}_{\mathrm{fd}}\right) / \mathrm{T}_{\mathrm{do}}^{\prime} \\
& \Delta \dot{\mathrm{E}}_{\mathrm{fd}}=-\left(1 / \mathrm{T}_{\mathrm{A}}\right) \Delta \mathrm{E}_{\mathrm{fd}}-\left(\mathrm{K}_{\mathrm{A}} / \mathrm{T}_{\mathrm{A}}\right) \Delta \mathrm{V}
\end{aligned}
$$

Fig. 2 shows the block diagram model of the system. This model is known as Heffron-Phillips model (Kundur, 1993). The model has some constants denoted by $K_{i}$. These constants are functions of the system parameters and the nominal operating condition. The nominal operating condition is given in the appendix.

Dynamic model in the state-space form

The dynamic model of the system in the state-space form is obtained as (3) (Kundur, 1993).

Fig. 2. Heffron-Phillips model of the electric power system.

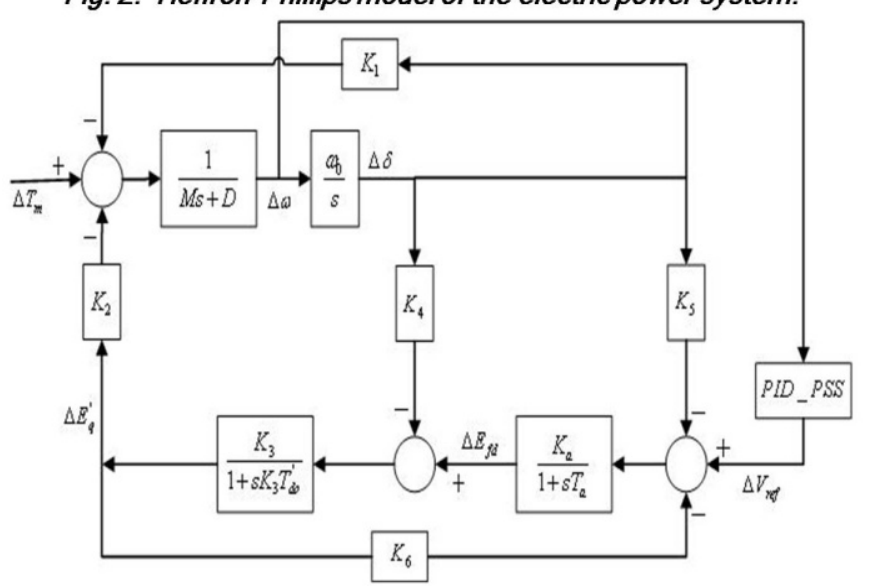

\section{Analysis}

In the nominal operating condition, the Eigen values of the system are obtained using analysis the state-space model of the system presented in (3) and these Eigen values are listed in Table 1. It is clearly seen that the system has two unstable poles at the right half plane and therefore the system is unstable and needs to power system stabilizer (PSS) for stability.

Table 1.The Eigen Values of the closed loop system.

\begin{tabular}{c}
\hline-4.2797 \\
-46.3666 \\
$0.1009+\mathrm{j} 4.758$ \\
$0.1009-\mathrm{j} 4.758$ \\
\hline
\end{tabular}

$\left[\begin{array}{c}\Delta \dot{\delta} \\ \Delta \dot{\omega} \\ \Delta \dot{\mathrm{E}}_{\mathrm{q}}^{\prime} \\ \Delta \dot{\mathrm{E}}_{\mathrm{fd}}^{\prime}\end{array}\right]=\left[\begin{array}{cccc}0 & \omega_{0} & 0 & 0 \\ -\frac{\mathrm{K}_{1}}{\mathrm{M}^{2}} & 0 & -\frac{\mathrm{K}_{2}}{\mathrm{M}} & 0 \\ -\frac{\mathrm{K}_{4}}{\mathrm{~T}_{\mathrm{do}}^{\prime}} & 0 & -\frac{\mathrm{K}_{3}}{\mathrm{~T}_{\mathrm{do}}^{\prime}} & \frac{1}{\mathrm{~T}_{\mathrm{do}}^{\prime}} \\ -\frac{\mathrm{K}_{\mathrm{A}} \mathrm{K}_{5}}{\mathrm{~T}_{\mathrm{A}}} & 0 & -\frac{\mathrm{K}_{\mathrm{A}} \mathrm{K}_{6}}{\mathrm{~T}_{\mathrm{A}}} & -\frac{1}{\mathrm{~T}_{\mathrm{A}}}\end{array}\right] \times\left[\begin{array}{c}\Delta \delta \\ \Delta \omega \\ \Delta \mathrm{E}_{\mathrm{q}} \\ \Delta \mathrm{E}_{\mathrm{fd}}\end{array}\right]+\left[\begin{array}{cc}0 & 0 \\ \frac{1}{\mathrm{M}} & 0 \\ 0 & 0 \\ 0 & \frac{\mathrm{K}_{\mathrm{A}}}{\mathrm{T}_{\mathrm{A}}}\end{array}\right] \times\left[\begin{array}{c}\Delta \mathrm{T}_{\mathrm{m}} \\ \Delta \mathrm{V}_{\mathrm{ref}}\end{array}\right]$

Power system stabilizer

A Power system stabilizer (PSS) is provided to improve the damping of power system oscillations. Power system stabilizer provides an electrical damping torque $\left(\Delta T_{m}\right)$ in phase with the speed deviation $(\Delta \omega)$ in order to improve damping of power system oscillations (Kundur, 1993). As referred before, many different methods have been applied to design power system stabilizers so far. In this paper a new optimal method based on the PSO is considered to tuning parameters of the PID type PSS. In the next section, the proposed method is briefly introduced and then designing the PID-PSS, based on the proposed methods, is done.

\section{The proposed method}

In this paper PSO method is considered for tuning PID type PSS. For more introductions, the PSO method is briefly introduced in the following subsection.

\section{Particle swarm optimization}

PSO was formulated by Edward and Kennedy in 1995. The thought process behind the algorithm was inspired by the social behavior of animals, such as bird flocking or fish schooling. PSO is similar to the continuous GA in that it begins with a random population matrix. Unlike the GA, PSO has no evolution operators such as crossover and mutation. The rows in the matrix are called particles (same as the GA chromosome). They contain the variable values and are not binary encoded. Each particle moves about the cost surface with a velocity. The particles update their velocities and positions based on the local and global best solutions as shown in (4) and (5) (Randy \& Sue, 2004):
Research article

CIndian Society for Education and Environment (iSee)
"Power system stabilizer" http://www.indjst.org
S.M.S.Bourojeni et al. Indian J.Sci.Technol. 
Indian Journal of Science and Technology

$V_{m, n}{ }^{\text {new }}=w \times V_{m, n}^{\text {old }}+\Gamma_{1} \times r_{1} \times\left(P_{m, n}^{\text {local best }}-P_{m, n}^{\text {old }}\right)+$

$\Gamma_{2} \times r_{2} \times\left(P_{m, n}\right.$ global best $-P_{m, n}$ old $)$

$P_{m, n}{ }^{\text {new }}=P_{m, n}{ }^{\text {old }}+\Gamma V_{m, n}^{\text {new }}$

Where: $V_{m, n}=$ particle velocity; $P_{m, n}=$ particle variables; $W=$ inertia weight; $r_{1}, r_{2}=$ independent uniform random numbers

$\Gamma_{1}=\Gamma_{2}=$ learning factors; $P_{m, n}{ }^{\text {local best }}=$ best local solution; $P_{m, n}{ }^{\text {global best }}=$ best global solution.

The PSO algorithm updates the velocity vector for each particle then adds that velocity to the particle position or values. Velocity updates are influenced by both the best global solution associated with the lowest cost ever found by a particle and the best local solution associated with the lowest cost in the present population. If the best local solution has a cost less than the cost of the current global solution, then the best local solution replaces the best global solution. The particle velocity is reminiscent of local minimizes that use derivative information, because velocity is the derivative of position. The advantages of PSO are that it is easy to implement and there are few parameters to adjust. The PSO is able to tackle tough cost functions with many local minima (Randy \& Sue, 2004).

\section{Design methodology}

In this section the PID type PSS parameters tuning based on the PSO is presented. The PID type PSS configuration is as (6).

$\mathrm{PID}-\mathrm{PSS}=\mathrm{K}_{\mathrm{P}}+\frac{\mathrm{K}_{\mathrm{I}}}{\mathrm{S}}+\mathrm{K}_{\mathrm{D}} \mathrm{S}$

The parameter $\Delta \mathrm{E}_{\text {ref }}$ is modulated to output of PSS and speed deviation $\Delta \omega$ is considered as input to PSS. The optimum values of $K_{P}, K_{l}$ and $K_{D}$ which minimize an array of different performance indexes are accurately computed using PSO. In this study the performance index is considered as (7). In fact, the performance index is the Integral of the Time multiplied Absolute value of the Error (ITAE).

ITAE $=\int_{0}^{\mathrm{t}} \mathrm{t}|\Delta \omega| \mathrm{dt}$

The parameter " $t$ " in performance index is the simulation time and is considered equal to $30 \mathrm{sec}$ for simulation. It is clear to understand that the controller with lower performance index is better than the other controllers. To compute the optimum parameter values, a 0.1 step change in the reference mechanical torque $(\Delta T m)$ is assumed and the performance index is minimized using PSO. In order to acquire better performance, number of particle, particle size, number of iteration, $\Gamma_{1}, \Gamma_{2}$, and $\Gamma$ are chosen as $12,3,50,2,2$ and 1 , respectively. Also, the inertia weight, $\mathrm{w}$, is linearly decreasing from 0.9 to 0.4 . It should be noted that PSO algorithm is run several times and then optimal set of PSS parameters is selected. The optimum values of the parameters $K_{P}, K_{I}$ and $K_{D}$ are obtained using PSO and summarized in the
Vol. 4 No. 4 (April 2011)

ISSN: 0974- 6846

Table 2. The boundaries of $K_{P}, K_{I}$ and $K_{D}$ are presented in the appendix.

Table 2. Obtained parameters of PID-PSS using PSO.
\begin{tabular}{|c|c|c|c|}
\hline PID parameters & $\mathrm{K}_{\mathrm{P}}$ & $\mathrm{K}_{\mathrm{I}}$ & $\mathrm{K}_{\mathrm{D}}$ \\
\hline Obtained value & 74.0115 & 49.558 & 13.1215 \\
\hline
\end{tabular}

Simulation results

In this section, the proposed PSO-PSS is applied to the under study system (single machine infinite bus power system). To show effectiveness of the proposed optimal PSO-PSS, A classical lead-lag PSS based on phase compensation technique (CPSS) is considered for comparing purposes. The detailed stepby-step procedure for computing the parameters of the classical lead-lag PSS (CPSS) using phase compensation technique is presented in (Kundur, 1993). Here, the CPSS has been designed and obtained as (8).

$$
\mathrm{CPSS}=\frac{35(0.3 \mathrm{~S}+1)}{(0.1 \mathrm{~S}+1)}
$$

In order to study the PSS performance under system uncertainties (controller robustness), three operating conditions are considered: 1) Nominal operating condition. 2) Heavy operating condition (20\% changing parameters from their typical values) and 3) Very heavy operating condition (50\% changing parameters from their typical values).

In the nominal operating condition, the Eigen values of the system with CPSS and PSO-PSS are obtained and listed in Table 3. It is clear to see that the Eigen values of

Table 3. The Eigen values of system with different PSSs.

\begin{tabular}{|c|c|c|}
\hline PSO-PSS & CPSS & Without PSS \\
\hline-0.7652 & -3.4256 & -4.2797 \\
-4.1015 & -4.0503 & -46.366 \\
-4.9711 & -46.3704 & $+0.1009+\mathrm{j} 4.758$ \\
-46.3735 & $-3.2991+\mathrm{j} 57.32$ & $+0.1009-\mathrm{j} 4.758$ \\
-406.2483 & $-3.2991-\mathrm{j} 57.32$ & \\
\hline
\end{tabular}

the system with PSO-PSS are farther than the imaginary axis and the system stability margin is more than CPSS method. Also to demonstrate the robustness performance of the proposed method, The ITAE is calculated following a $10 \%$ step change in the reference mechanical torque $\left(\Delta T_{m}\right)$ at all operating conditions (Nominal, heavy \&Very heavy) and results are shown at Table 4. Following step change at $\Delta T_{m}$, the PSO-PSS has better performance than the CPSS at all operating conditions. Where, the PSO-PSS has lower ITAE index in comparison with CPSS, therefore the PSO-PSS can damp power system oscillations more successfully. Also the control effort signal is one of the most important factors to compare responses. The parameter $\Delta V_{\text {ref }}$ which is shown in Fig. 2 is the output of controller and is considered as the control effort signal. The control effort signal is computed as (9).

Table 4. The calculated ITAE.

\begin{tabular}{|l|c|c|}
\hline \multicolumn{1}{|c|}{ Condition } & PSO-PSS & CPSS \\
\hline Nominal operating condition & $3.2547 \times 10^{-4}$ & $5.5686 \times 10^{-4}$ \\
\hline Heavy operating condition & $3.0095 \times 10^{-4}$ & $7.2451 \times 10^{-4}$ \\
\hline Very heavy operating condition & $2.4291 \times 10^{-4}$ & $8.9021 \times 10^{-4}$ \\
\hline
\end{tabular}

Research article

CIndian Society for Education and Environment (iSee)

"Power system stabilizer"

http://www.indjst.org
S.M.S.Bourojeni et al. Indian J.Sci.Technol. 
Fig. 3. Dynamic responses $\Delta \omega$ following 0.1 step in the reference mechanical torque $(\triangle T m)$

a: Nominal operating condition b: Heavy operating
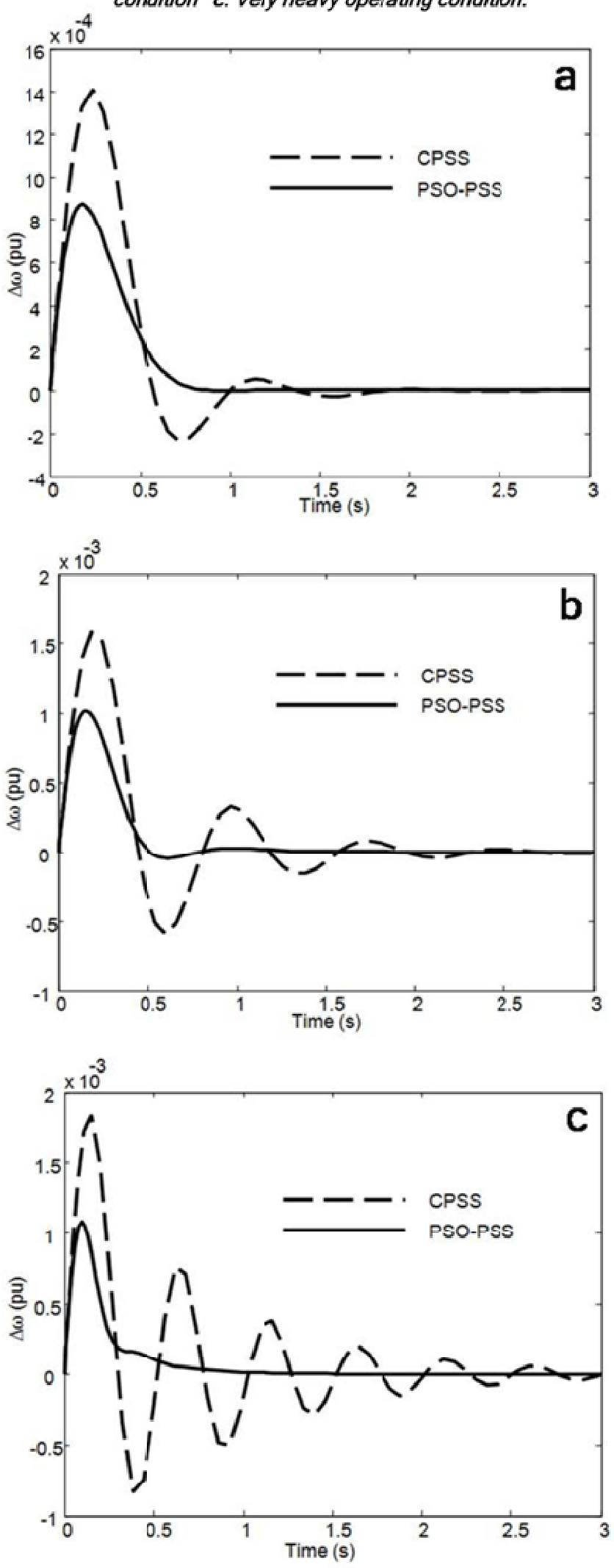

Control_Effort $=\int_{0}^{\mathrm{t}} \mathrm{t}|\Delta \mathrm{Vref}| \mathrm{dt}$
The control effort has been calculated following a $10 \%$ step change in the reference mechanical torque $\left(\Delta T_{m}\right)$ at all operating conditions (Nominal, Heavy and Very heavy) and results are shown at Table 5 . It is clear to see that following step change at $\Delta T_{m}$, the PSO-PSS has lower control effort than the other methods at all operating conditions. This means that the PSO-PSS damps power system oscillations by injecting lower control signal. Lower control effort signal of the PSO-PSS can lead to a simple and also lower cost implementation of the controller. Although the control effort and performance index results are enough to compare the methods, but it can be more useful to show responses in figures. Fig. 3 shows $\Delta \omega$ at nominal, heavy and very heavy operating conditions following $10 \%$ step change in the reference mechanical torque $\left(\Delta T_{m}\right)$. It is clear to see that between all operating conditions, the PSO-PSS has better performance than the other method in mitigating oscillations. PSO-PSS characteristics in the damping power system oscillations are in the range of acceptable. Eventually between two methods, the PSO-PSS has a very significant better performance than CPSS. The CPSS ability in damping power system oscillations goes to unstable and large oscillations with changing system operating conditions and under heavy loads.

Table 5. The calculated control effort signal.

\begin{tabular}{|l|c|c|}
\hline \multicolumn{1}{|c|}{ Condition } & PSO-PSS & CPSS \\
\hline Nominal operating condition & 0.0689 & 0.0327 \\
\hline Heavy operating condition & 0.0654 & 0.0490 \\
\hline Very heavy operating condition & 0.0610 & 0.0721 \\
\hline
\end{tabular}

\section{Conclusion}

In this paper a new optimal PID type PSS based on PSO (PSO-PSS) method has been successfully proposed. The design strategy includes enough flexibility to set the desired level of stability and performance, and to consider the practical constraints by introducing appropriate uncertainties. Also the final designed PSOPSS is low order and its implementation is easy and cheap. The proposed method was applied to a typical single machine infinite bus power system containing system parametric uncertainties and various loads conditions. The simulation results demonstrated that the designed PSO-PSS is capable of guaranteeing the robust stability and robust performance of the power system under a wide range of system uncertainties.

\section{Appendix}

The nominal parameters and operating conditions of the system are listed in Table 6 . The boundaries of $K_{P}, K_{l}$ and $K_{D}$ for optimal search are listed in Table 7. 
Table 6. The nominal system parameters.

\begin{tabular}{|l|c|c|c|}
\hline \multirow{2}{*}{ Generator } & $\begin{array}{c}\mathrm{M}=10 \\
\mathrm{Mj} / \mathrm{MVA}\end{array}$ & $\mathrm{T}^{\prime}{ }_{\mathrm{do}}=7.5 \mathrm{~s}$ & $\mathrm{X}_{\mathrm{d}}=1.68$ p.u. \\
\cline { 2 - 4 } & $\mathrm{X}_{\mathrm{q}}=1.6 \mathrm{p} . \mathrm{u}$. & $\mathrm{X}^{\prime} \mathrm{d}=0.3 \mathrm{p} . \mathrm{u}$. & $\mathrm{D}=0$ \\
\hline $\begin{array}{l}\text { Excitation } \\
\text { system }\end{array}$ & & $\mathrm{K}_{\mathrm{a}}=50$ & $\mathrm{~T}_{\mathrm{a}}=0.02 \mathrm{~s}$ \\
\hline Transformer & & $\mathrm{X}_{\mathrm{tr}}=0.1$ p.u. & \\
\hline $\begin{array}{l}\text { Transmission } \\
\text { lines }\end{array}$ & $\mathrm{X}_{\mathrm{te} 1}=0.5$ p.u. & $\mathrm{X}_{\mathrm{te} 2}=0.9$ p.u. & \\
\hline $\begin{array}{l}\text { Operating } \\
\text { condition }\end{array}$ & $\mathrm{V}_{\mathrm{t}}=1.05$ p.u. & $\mathrm{P}=1$ p.u. & $\mathrm{Q}=0.2$ p.u. \\
\hline
\end{tabular}

Table 7. The boundaries of $K_{P}, K_{/} \& K_{D}$.

\begin{tabular}{|l|c|c|c|}
\hline Parameters & $1 \leq \mathrm{K}_{\mathrm{P}} \leq 100$ & $1 \leq \mathrm{K}_{I} \leq 100$ & $1 \leq \mathrm{K}_{\mathrm{D}} \leq 100$ \\
\hline
\end{tabular}

\section{Acknowledgement}

The first and second authors have equal participation in this paper.

\section{References}

1. Bouhamida M, Mokhatri A and Denai MA (2005) Power system stabilizer design based on robust control techniques. ACSE J. 5, 33-41.

2. Chatterjee A, Ghoshal SP and Mukherjee V (2009). A comparative study of single input and dual input power system stabilizer by hybrid evolutionary programming. World Cong. on Nature \& Biologically Inspired Computing. pp:1047-1059.

3. Dubey M (2007) Design of genetic algorithm based fuzzy logic power system stabilizers in multi machine power system. Int. Conf. on soft computing \& intelligent systems. pp:214-219.

4. Gupta R, Bandopadhya B and Kulkarni AM (2005) Power system stabilizer for multi machine power system using robust decentralized Periodic output feedback. IEE Proc. control theory application. 152, 38.

5. Hwanga GH, Kimb DW, Leec JH and Joo Y (2008) Design of fuzzy power system stabilizer using adaptive evolutionary algorithm. Engg. Appl. Artificial Intelligence. 21, 86-96.

6. Jiang P, Yan W and Weigu (2008) PSS parameter optimization with genetic algorithms. DRPT 2008, Nanjing China. pp: 900-903.

7. Kundur $P$ (1993) Power system stability and control. McGraw-Hill, Inc., NY. pp:700-822.

8. Linda MM and Nair NK (2010) Dynamic stability enhancement with fuzzy based power system stabilizer tuned by hottest non-traditional optimization technique. Second Int. Conf. on Computing, Communication \& Networking Technol. pp:1-5.

9. Liu W, Venayagamoorthy GK and Wunsch DC (2005) A heuristic dynamic programming based power system stabilizer for a turbo generator in a single machine power system. IEEE Trans. on Industry Appl. 4, 1377-1385.
10.Mocwane $\mathrm{K}$ and Folly KA (2007) Robustness evaluation of $\mathrm{H}_{\infty}$ power system stabilizer. IEEE PES Power Africa Conf. Exhibition. pp:16-20.

11. Nambu $M$ and Ohsawa $Y$ (1996) Development of an advanced power system stabilizer using a strict linearization approach. IEEE Trans. on Power Sys. 11, 813-818.

12. Randy LH and Sue EH (2004) Practical genetic algorithms. $2^{\text {nd }}$ edn., John Wiley \& Sons. pp:25-67.

13. Sil A, Gangopadhyay TK, Paul S and Maitra AK (2009) Design of robust power system stabilizer using $\mathrm{H}^{\infty}$ mixed sensitivity technique. $3^{\text {rd }}$ Int. Conf. on Power Sys. India. pp:1-4.

14.Sudha KR, Vakula VS and Vijayasanthi R (2009) Particle swarm optimization in fine tuning of PID fuzzy logic power system stabilizer. Int. Conf. on Advances in Computing, Control \& Telecommunication Technol. pp:356-358.

15.Sumathi N, Selvan MP and Kumaresan N (2007) A hybrid genetic algorithm based power system stabilizer. Int. conf. on intelligent \& advanced systems. pp:876-881.

16. Yassami H, Darabi A and Rafiei SMR (2010) Power system stabilizer design using strength pareto multiobjective optimization approach. Electric Power Systems Res. 80, 838-846. 